\title{
The Role of Water Vapour in Earth's Energy Flows
}

\author{
Richard P. Allan
}

Received: 5 September 2011/Accepted: 28 October 2011/Published online: 24 November 2011

(C) Springer Science+Business Media B.V. 2011

\begin{abstract}
Water vapour modulates energy flows in Earth's climate system through transfer of latent heat by evaporation and condensation and by modifying the flows of radiative energy both in the longwave and shortwave portions of the electromagnetic spectrum. This article summarizes the role of water vapour in Earth's energy flows with particular emphasis on (1) the powerful thermodynamic constraint of the Clausius Clapeyron equation, (2) dynamical controls on humidity above the boundary layer (or freetroposphere), (3) uncertainty in continuum absorption in the relatively transparent "window" regions of the radiative spectrum and (4) implications for changes in the atmospheric hydrological cycle.
\end{abstract}

Keywords Water vapour $\cdot$ Hydrological cycle $\cdot$ Radiative processes $\cdot$ Climate

\section{Introduction}

Water vapour is of central importance to energy flows within the climate system, by modulating the transmission of radiative energy between the surface, atmosphere and space and also through transferring latent heat from the surface (evaporation) to the atmosphere (precipitation) ${ }^{1}$ following transport of moisture within the atmosphere (Fig. 1). There are many aspects of these processes that are well understood, based upon robust physics, detailed process modelling and measurements ranging from laboratory experiments up to satellite observations of the entire globe (e.g., Held and Soden 2006; Sherwood et al. 2010a, b). One of the fundamental controls on the climate system is the Clausius Clapeyron equation which provides a powerful constraint on how saturated moisture content varies with air temperature:

\footnotetext{
${ }^{1}$ Latent heat released by condensation is retained in the atmosphere only after the water is removed by precipitation to the surface before re-evaporation in the atmosphere can occur.
}

R. P. Allan $(\bowtie)$

Department of Meteorology/National Centre for Atmospheric Science,

University of Reading, Reading, UK

e-mail: r.p.allan@ reading.ac.uk 


$$
\frac{1}{q_{\mathrm{s}}} \frac{\mathrm{d} q_{\mathrm{s}}}{\mathrm{d} T} \approx \frac{1}{e_{\mathrm{s}}} \frac{\mathrm{d} e_{\mathrm{s}}}{\mathrm{d} T}=\frac{L}{R_{v} T^{2}}= \begin{cases}0.14 \mathrm{~K}^{-1} & \mathrm{~T}=200 \mathrm{~K} \\ 0.07 \mathrm{~K}^{-1} & \mathrm{~T}=273 \mathrm{~K} \\ 0.06 \mathrm{~K}^{-1} & \mathrm{~T}=300 \mathrm{~K}\end{cases}
$$

where $q_{\mathrm{s}}$ is the saturation specific humidity in $\mathrm{kg}$ water vapour per kg moist air, $e_{\mathrm{s}}$ is the saturation water vapour pressure $(\mathrm{Pa}), T$ is air temperature $(\mathrm{K}), L$ is the latent heat of vapourisation $\left(2.5 \times 10^{6} \mathrm{~J} \mathrm{~kg}^{-1}\right), R_{\mathrm{v}}$ is the gas constant for water vapour $\left(461 \mathrm{~J} \mathrm{~K}^{-1} \mathrm{~kg}^{-1}\right)$ and the first term approximates to the second term ${ }^{2}$. Equation 1 therefore predicts increases in water vapour of order $6-7 \% / \mathrm{K}$ for temperatures close to the surface assuming fixed relative humidity; further discussion is given by O'Gorman and Muller (2010).

Observations and modelling indicate that column integrated water vapour, averaged over sufficiently large scales, increases approximately exponentially with atmospheric temperature (Raval and Ramanathan 1989) as predicted by (1). The absorption of infra-red radiation by water vapour increases approximately in proportion to the logarithm of its concentration. These two powerful constraints generate an amplifying effect on changes in Earth's climate, enhancing the response of surface temperature to a radiative forcing or internal variability, and the resultant positive water vapour feedback is relatively "forgiving" in the sense that substantial excursions away from these basic physical constraints are required to alter its nature.

\section{Radiative effects of water vapour}

Absorption of radiation by water vapour in distinct bands across the electromagnetic spectrum, relating to vibrational and rotational modes of molecular excitation, is reasonably well characterised by detailed measurements and theory. Nevertheless, there remains a question as to the physical basis of radiative transfer away from the absorption line centres, important for the atmospheric "windows" in which radiative energy is more able to pass relatively unimpeded through the atmosphere compared to band centres. Although the continuum absorption in these windows, and its dependence on pressure and temperature, is now much better observed and characterised, there remains a lively debate on the underlying physical causes of this continuum. The historical perspective underpinning the development of a theory of water vapour continuum absorption has led to recent developments and experimental campaigns leading to new insights into this uncertain aspect of how water vapour influences the flows of radiative energy through the atmosphere (Shine et al. 2012). Although improved representation of the water vapour continuum is likely to reduce uncertainty in Earth's radiative energy budget only marginally, it may have implications for the retrieval of physical quantities from space and therefore how we observe Earth's climate system. There also remain important questions as to the consistency of water vapour absorption of solar radiation in climate models, with implications for responses of the hydrological cycle (Takahashi 2009).

\section{Dynamical controls on the water vapour greenhouse effect}

While the radiative effects of water vapour contribute uncertainty to the simulation of radiative fluxes, a greater source of uncertainty in simulating radiative fluxes regionally is

\footnotetext{
${ }^{2}$ The first term is larger than the second term by a factor $q_{\mathrm{s}} p / \epsilon e_{\mathrm{s}}=p /\left(p-e_{\mathrm{s}}(1-\epsilon)\right)=1+q_{\mathrm{s}}((1 / \epsilon)-1)$ $\sim 1+0.6 q_{s}$ assuming fixed pressure, where $\varepsilon=0.622$ is the ratio of gas constants for dry air and water vapour. For a surface pressure of $1,000 \mathrm{hPa}$ and using the August-Roche-Magnus empirical approximation for $e_{\mathrm{s}}(T)$, the first term exceeds the second term by around $0.2 \%$ at $273 \mathrm{~K}$ and by $1 \%$ at $300 \mathrm{~K}$.
} 


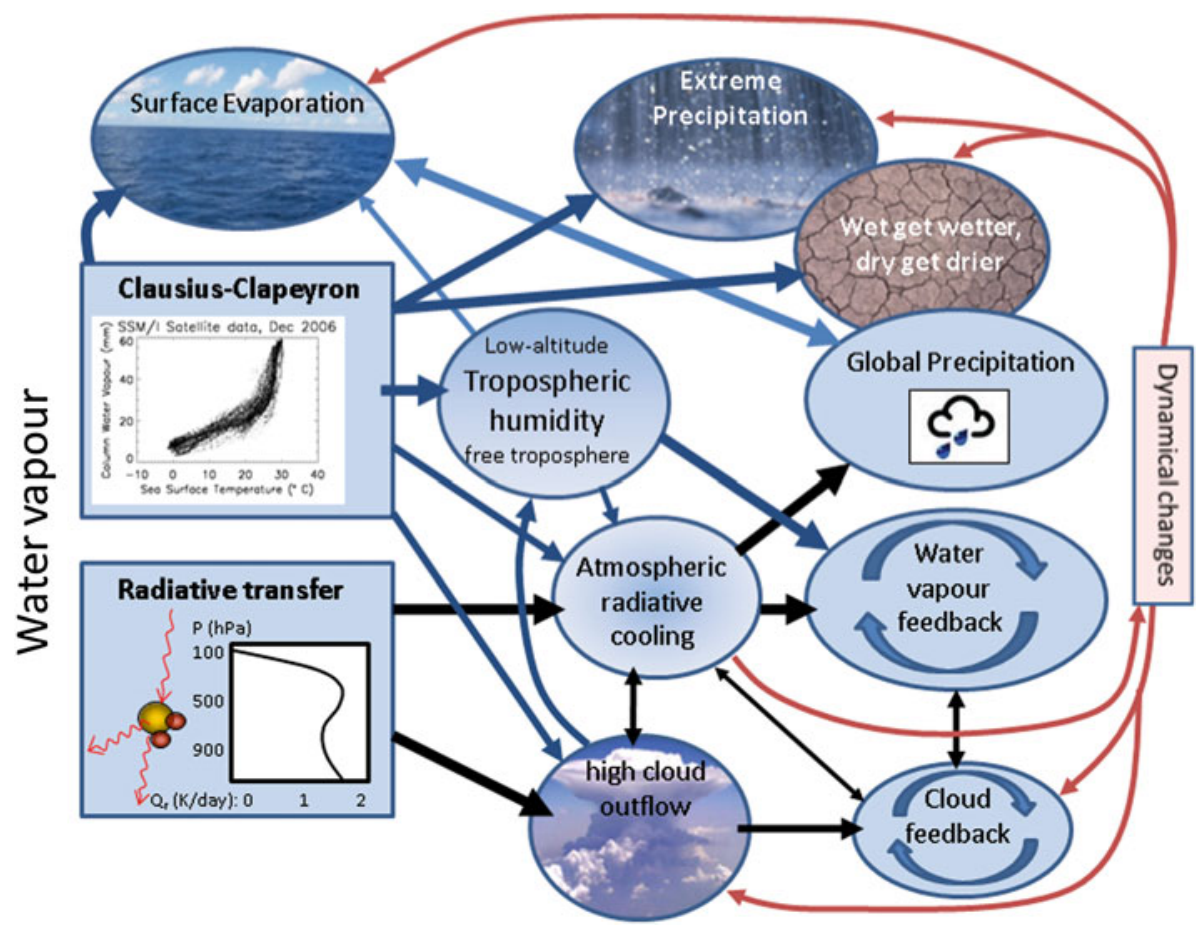

Fig. 1 The role of water vapour in Earth's energy flows: a simplistic schematic representation of some of the links between water vapour and energetic processes in the climate system. Arrow colours denote the primary driving physical process, including radiative transfer (black), thermodynamics (blue) and dynamics (red)

the distribution and concentration of water vapour throughout the atmosphere. The maintenance of the present-day distribution of relative humidity $\left(\mathrm{RH}=e / e_{\mathrm{s}}\right)$, a diagnostic of how close the atmospheric water vapour pressure $(e)$ is to the saturation vapour pressure (often expressed as a percentage), is also fundamental to positive water vapour feedback. Relative humidity within the subsiding branches of the tropical circulation is crucial in modulating the emission of infra-red radiation to space (Spencer and Braswell 1997; Allan et al. 1999; Brogniez et al. 2005).

The present day distribution of humidity is reasonably well approximated using a "point of last saturation" perspective, specifically that the amount of water vapour is determined by the temperature at which the considered parcel of air last experienced $100 \%$ relative humidity (Pierrehumbert 1998; Sherwood et al. 2010b). This is also well approximated by considering the circulation as being driven by subsidence induced by radiative cooling in the descending branches of the tropical circulation (e.g., Folkins et al. 2002), but may only apply to certain regions of the upper troposphere since mixing with lower-level humidity and transport from the mid-latitudes have also been shown to dominate in model simulations and reanalyses (Galewsky et al. 2005). Cloud microphysics may also modify the humidity distribution of the free-troposphere. However, modelling studies demonstrate that cloud ice plays a relatively minor role in moistening the upper troposphere compared to water vapour (John and Soden 2006). This suggests that it is inherently large-scale processes that maintain and control the relative humidity distribution at scales that are therefore resolvable by climate models simulations. 
The precise dynamical controls on the "free" tropospheric humidity (above the influence of the boundary layer) require improved characterization since they may have important bearing on the overall responses of the humidity distribution (and indirectly on cloud), and hence the flows of longwave radiative energy, in a warming climate. Important in regulating these energy flows are the driest regions of the upper troposphere. Roca et al. (2012) find a dual control on one of the driest regions of the upper troposphere, located above the eastern Mediterranean: air is advected from both tropical convective regimes and mid-latitude disturbances, and the relative contribution of these two source regions exerts an appreciable affect on the relative humidity over these regions (see also Galewsky et al. 2005).

Small yet systematic changes in relative humidity in a warming climate contribute towards the magnitude of water vapour feedback and aspects of the hydrological cycle and energy flows. It has long been appreciated that a warming climate is associated with small reductions in subtropical free-tropospheric relative humidity, based upon climate model simulations (e.g., Mitchell et al. 1987; Sherwood et al. 2010a) and recent observations (Minschwaner and Dessler 2004), which reduces the magnitude of the water vapour feedback by around 5\% relative to that anticipated from the Clausius Clapeyron equation alone (e.g., Soden and Held 2006). The mechanism for this change can be related to the outflow temperature of deep convection in the tropics and linked to the altitude of neutral buoyancy. This is determined by the decline in longwave radiative cooling with altitude in the upper troposphere due to reduced water vapour concentrations, again determined by the Clausius Clapeyron equation (Zelinka and Hartmann 2010). The robust physics relating to radiative transfer and Eq. 1 appears to explain positive feedback from high altitude clouds (Fig. 1) in the tropics simulated by climate models (Zelinka and Hartmann 2010; Soden and Vecchi 2011).

\section{The atmospheric hydrological cycle}

Near to the surface, small increases in relative humidity with warming, combined with diminishing wind stress (Gastineau and Soden 2011) and reduced near surface temperature lapse rate, appear to explain a reduced dependence of surface evaporation on temperature $(2-3 \% / \mathrm{K})$ compared to that expected from the Clausius Clapeyron equation alone, sometimes referred to as a "muted response" (Richter and Xie 2008). Detecting the small changes in relative humidity over the oceans simulated by climate model projections is difficult. However, declines in relative humidity over moisture-limited land regions as global temperatures rise may be more apparent: projected and observed increases in land minus ocean temperature contrast (e.g., Lambert and Chiang 2007) coupled with the dominance of the oceans as a source of moisture for precipitation over land (e.g., Gimeno et al. 2010) may have contributed to recent reductions in relative humidity over land since 2000 (Simmons et al. 2010).

The present-day observed distribution of water vapour within the atmosphere is also an important diagnostic of the hydrological cycle. Substantial model biases in this distribution (John and Soden 2007) may therefore be symptomatic of inadequacies in the simulation of the global water cycle. The atmospheric hydrological cycle is intimately linked with Earth's energy flows through water vapour, from its direct impact upon the surface and atmospheric radiative budgets and also its influence on clouds and precipitation through convergence of moisture (Mitchell et al. 1987; Sherwood et al. 2010b). The radiative properties of water vapour, including continuum absorption and emission, are crucial in explaining an enhanced longwave radiative cooling of the atmosphere (Stephens and Ellis 2008; Allan 
2009; Previdi 2010) and reduced radiative cooling of the surface as the climate warms. Recent advances in understanding of the links between precipitation and radiative energy budgets (e.g., Andrews et al. 2010) are discussed in detail by O'Gorman et al. (2012).

The dominance of radiative-convective processes in the tropics for maintaining temperature lapse rate (the decline in air temperature with altitude) helps to determine the increased rate of radiative cooling with increasing surface and atmospheric temperature (Lambert and Webb 2008; Allan 2009) which in turn explains why global precipitation increases with warming in the present climate at the rate of around $2-3 \% / \mathrm{K}$ in climate models, a "muted" response relative to the increases in low-level water vapour of around $6-7 \% / \mathrm{K}$ (Allan 2011). The differing rates of increase in water vapour and precipitation are reconciled in climate model simulations through changes in tropical circulation, in particular a reduction in the strength of the Walker circulation (Vecchi et al. 2006), although both external forcing and internally generated variability are thought to have contributed to an observed weakening over the twentieth century (Power and Kociuba 2011).

The physical basis for decreased tropical circulation can be understood in terms of the atmospheric mass flux $(M)$ relating precipitation $(P$, here in units of $\mathrm{kg} / \mathrm{s})$ with low-level specific humidity $(q)$ ignoring the small return flow of moisture at upper levels (Held and Soden 2006) (although see also Zahn and Allan 2011):

$$
P \approx M q .
$$

Clearly, for Eq. 2 to be true, if $P$ is constrained by the energy balance to rise at $2-3 \% / \mathrm{K}$ and $q$ is constrained to rise in accordance with Eq. 1 at around $6-7 \% / \mathrm{K}$, then $M$ must diminish (Held and Soden 2006). Another perspective, relating to earlier discussion of radiatively driven subsidence, links vertical motion, $w$ (km/day), to radiative cooling, $Q(\mathrm{~K} /$ day), and the deviation from dry adiabatic lapse rate, or static stability, $\sigma(\mathrm{K} / \mathrm{km})($ Knutson and Manabe 1995):

$$
w=\frac{Q}{\sigma} .
$$

In the tropics, rising temperatures are associated with a conservation of moist adiabatic lapse rate, leading to increased static stability. Therefore, the amount of subsidence required to balance $Q$ through adiabatic heating is diminished in a warmer climate. Since the increase in stability averaged over the troposphere scales with boundary layer moisture, $q$, in accordance with Eq. $1(6-7 \% / \mathrm{K})$, while the radiative cooling enhances at $2-3 \% / \mathrm{K}$, the stability changes dominate and the tropical circulation reduces (Held and Soden 2006), analogous to the situation in Eq. 2 (see also Chou and Chen 2010).

Of importance to climate impacts relating to the role of water vapour in Earth's energy flows is how precipitation and its extremes will respond to warming regionally over decadal time-scales. Locally, large-scale precipitation is dependent upon convergence of low-level moisture from surrounding regions. The Clausius-Clapeyron equation therefore provides a substantial constraint upon changes in intense precipitation events (Trenberth 2011; Sugiyama et al. 2010; Allan et al. 2010; O'Gorman and Schneider 2009; Bengtsson et al. 2009). O'Gorman and Schneider (2009) argue that the condensation rate $(c)$ at a given level in the atmosphere associated with an extreme precipitation event scales as:

$$
c=-\left.\omega \frac{\mathrm{d} q_{\mathrm{s}}}{\mathrm{d} p}\right|_{\theta^{*}},
$$


where $\theta^{*}$ is the equivalent potential temperature, denoting the change in $q_{\mathrm{s}}$ along a moist adiabat, and $\omega$ is the vertical pressure velocity in $\mathrm{Pa} / \mathrm{s}$. Assuming that almost all of the surface moisture is condensed in the storm, Eq. 4 scales with surface $q_{\mathrm{s}}$ at the rates indicated in Eq. 1. Changes in $\omega$ also strongly influence $c$ and therefore precipitation and latent heating within storms.

The increased supply of low-level water vapour for intense rainfall is maintained in wet regions by the convergence of moisture transported from dry ocean basins of high evaporation (Gimeno et al. 2010) and may be understood in terms of the moisture balance equation (e.g., Held and Soden 2006):

$$
\frac{\mathrm{d}(P-E)}{\mathrm{d} T} \approx \alpha(P-E)
$$

where $E$ is surface evaporation and $\alpha$ is equal to the terms in Eq. 1. Using this approach, Held and Soden (2006) demonstrate that Precipitation minus Evaporation $(P-E)$ patterns are enhanced in a warming world. Since evaporation changes are relatively uniform, this explains why Eq. 5 is manifest most strongly as contrasting precipitation responses in the wet and dry regions of the tropics (e.g., Chou et al. 2007; Allan et al. 2010). An alternative perspective is to again consider the energy balance: latent heating through condensation of water droplets and eventual precipitation must be balanced by cooling through radiative processes and dry static energy transport, assuming other terms such as sensible heating are small (Muller and O'Gorman 2011); this may also have bearing upon the viability and stability of monsoon systems (Levermann et al. 2009).

\section{Concluding remarks}

While thermodynamics and radiative transfer theory provide a robust physical basis for water vapour feedback and changes in the hydrological cycle (Fig. 1), some of the details of the role of water vapour on Earth's energy flows remain to be clarified, in particular with regard to changes in the global water cycle. The Clausius Clapeyron constraint upon precipitation intensity appears to be less clear over tropical regions in models due to a varied response in updraft velocity ( $\omega$ in (4)) within simulated extreme precipitation events (O'Gorman and Schneider 2009; Allan et al. 2010; Sugiyama et al. 2010) and there are substantial deviations from the anticipated $6-7 \% / \mathrm{K}$ response in observational datasets (Lenderink and van Meijgaard 2010; Haerter et al. 2010) relating to spatial and temporal sampling scales as well as contrasting physical mechanisms such as atmospheric stabilisation or storm invigoration through intense latent heating or moisture limitation (Hardwick-Jones et al. 2010).

It is also plausible that temporary increases in the strength of the tropical circulation may yield larger precipitation responses than anticipated (e.g., Wentz et al. 2007) relative to secular trends (e.g., Semenov and Bengtsson 2002). There are also some limited observationally based analyses which suggest increases in tropical circulations (e.g., Sohn and Park 2010; Zahn and Allan 2011) although these changes may be sensitive to the assimilation of erroneous temperature lapse rate observations in the reanalyses employed (Held and Soden 2006). It is not currently clear what mechanisms drive decadal variability, nor whether the observing systems are of sufficient stability to capture such changes accurately (Trenberth 2002). A further related example relates to stratospheric water vapour which also appears to show substantial decadal variability, potentially influencing decadal temperature trends (Solomon et al. 2010), but a physical mechanism for the 
variation remains unclear. The characteristics of decadal fluctuations in global circulation, precipitation and upper tropospheric/lower stratospheric water vapour and their causative mechanisms currently remain an open question in relation to the role of water vapour in Earth's energy flows.

Acknowledgments Thanks to Paul O'Gorman, Remy Roca, Keith Shine, Brian Soden and two anonymous reviewers for comments and corrections on the original manuscript and for their input, along with B.-J. Sohn, Andrew Dessler and many others, to the International Space Sciences Institute Workshop Session on Observing and modelling Earth's energy flows. R Allan was supported by the UK Natural Environment Research Council PREPARE project (NE/G015708/1).

\section{References}

Allan RP (2009) Examination of relationships between clear-sky longwave radiation and aspects of the atmospheric hydrological cycle in climate models, reanalyses, and observations. J Climate 22:3127-4145

Allan RP (2011) Human influence on rainfall. Nature 470:344-345

Allan RP, Shine KP, Slingo A, Pamment JA (1999) The dependence of clear-sky outgoing longwave radiation on surface temperature and relative humidity. Q J R Meteorol Soc 125:2103-2126

Allan RP, Soden BJ, John VO, Ingram W, Good P (2010) Current changes in tropical precipitation. Environ Res Lett 5. doi:10.1088/1748-9326/5/2/025205

Andrews T, Forster PM, Boucher O, Bellouin N, Jones A (2010) Precipitation, radiative forcing and global temperature change. Geophys Res Lett 37:L14701. doi:10.1029/2010GL043991

Bengtsson L, Hodges KI, Keenlyside N (2009) Will extra-tropical storms intensify in a warmer climate? J Climate 22:2276-2301

Brogniez H, Roca R, Picon L (2005) Evaluation of the distribution of subtropical free tropospheric humidity in AMIP-2 simulations using METEOSAT water vapor channel data. Geophys Res Lett 32:L19708

Chou C, Chen C (2010) Depth of convection and the weakening of tropical circulation in global warming. J Climate 23:3019-3030

Chou C, Tu J, Tan P (2007) Asymmetry of tropical precipitation change under global warming. Geophys Res Lett 34:L17708. doi:10.1029/2007GL030327

Folkins I, Kelly KK, Weinstock EM (2002) A simple explanation of the increase in relative humidity between 11 and $14 \mathrm{~km}$ in the tropics. J Geophys Res 107:4736. doi:10.1029/2002JD002185

Galewsky J, Sobel A, Held I (2005) Diagnosis of subtropical humidity dynamics using tracers of last saturation. J Atmos Sci 62:3353-3367

Gastineau G, Soden BJ (2011) Evidence for a weakening of tropical surface wind extremes in response to atmospheric warming. Geophys Res Lett 38:L09706. doi:10.1029/2011GL047138

Gimeno L, Drumond A, Nieto R, Trigo RM, Stohl A (2010) On the origin of continental precipitation. Geophys Res Lett 37:L13804

Haerter JO, Berg P, Hagemann S (2010) Heavy rain intensity distributions on varying time scales and at different temperatures. J Geophys Res 115:D17102

Hardwick-Jones R, Westra S, Sharma A (2010) Observed relationships between extreme sub-daily precipitation, surface temperature, and relative humidity. Geophys Res Lett 37:L22805

Held IM, Soden BJ (2006) Robust responses of the hydrological cycle to global warming. J Climate 19: $5686-5699$

John VO, Soden BJ (2006) Does convectively-detrained cloud ice enhance water vapor feedback? Geophys Res Lett 33:L20701

John VO, Soden BJ (2007) Temperature and humidity biases in global climate models and their impact on climate feedbacks. Geophys Res Lett 34:L18704. doi:10.1029/2007GL030429

Knutson TR, Manabe S (1995) Time-mean response over the tropical Pacific to increased $\mathrm{CO}_{2}$ in a coupled ocean-atmosphere model. J Climate 8:2181-2199

Lambert FH, Chiang JCH (2007) Control of land-ocean temperature contrast by ocean heat uptake. Geophys Res Lett 34:L13704

Lambert FH, Webb MJ (2008) Dependency of global mean precipitation on surface temperature. Geophys Res Lett 35:L16706. doi:10.1029/2008GL034838

Lenderink G, van Meijgaard E (2010) Linking increases in hourly precipitation extremes to atmospheric temperature and moisture changes. Environ Res Lett 5:025208 
Levermann A, Schewe J, Petoukhov V, Held H (2009) Basic mechanism for abrupt monsoon transitions. Proc Nat Acad Sci 106:20,572-20,577

Minschwaner K, Dessler AE (2004) Water vapor feedback in the tropical upper troposphere: model results and observations. J Climate 17:1272-1282

Mitchell J, Wilson CA, Cunnington WM (1987) On $\mathrm{CO}_{2}$ climate sensitivity and model dependence of results. Q J R Meteorol Soc 113:293-322

Muller CJ, O'Gorman PA (2011) An energetic perspective on the regional response of precipitation to climate change. Nat Climate Change 1:266-271

O'Gorman PA, Muller CJ (2010) How closely do changes in surface and column water vapor follow Clausius-Clapeyron scaling in climate change simulations. Environ Res Lett 5:025207. doi: $10.1088 / 1748-9326 / 5 / 2 / 025207$

O'Gorman PA, Schneider T (2009) The physical basis for increases in precipitation extremes in simulations of 21st-century climate change. Proc Nat Acad Sci 106:14,773-14,777

O'Gorman PA, Allan RP, Byrne MP, Previdi M (2012) Energetic constraints on precipitation under climate change. Surv Geophys. doi:10.1007/s10712-011-9159-6

Pierrehumbert RT (1998) Lateral mixing as a source of subtropical water vapor. Geophys Res Lett 25:151-154

Power SB, Kociuba G (2011) What caused the observed 20th century weakening of the Walker circulation? J Climate (in press). doi:10.1175/2011JCLI4101.1

Previdi M (2010) Radiative feedbacks on global precipitation. Environ Res Lett 5:025-211

Raval A, Ramanathan V (1989) Observational determination of the greenhouse effect. Nature 342:758-761

Richter I, Xie SP (2008) The muted precipitation increase in global warming simulations: a surface evaporation perspective. J Geophys Res 113:D24118. doi:10.1029/2008JD010561

Roca R, Guzman R, Lemond J, Meijer J, Picon L, Brogniez H (2012) Tropical and extra-tropical influences on the distribution of free tropospheric humidity over the intertropical belt. Surv Geophys (this volume)

Semenov V, Bengtsson L (2002) Secular trends in daily precipitation characteristics: greenhouse gas simulation with a coupled AOGCM. Climate Dyn 19:123-140

Sherwood SC, Ingram W, Tsushima Y, Satoh M, Roberts M, Vidale PL, O'Gorman PA (2010a) Relative humidity changes in a warmer climate. J Geophys Res 115:D09104. doi:10.1029/2009JD012585

Sherwood SC, Roca R, Weckwerth TM, Andronova NG (2010b) Tropospheric water vapor, convection, and climate. Rev Geophys 48:RG2001

Shine KP, Ptashnik IV, Rädel G (2012) The water vapour continuum: brief history and recent developments. Surv Geophys (this volume)

Simmons AJ, Willett KM, Jones PD, Thorne PW, Dee DP (2010) Low-frequency variations in surface atmospheric humidity, temperature, and precipitation: inferences from reanalyses and monthly gridded observational data sets. J Geophys Res 115:D01110. doi:10.1029/2009JD012442

Soden BJ, Held IM (2006) An assessment of climate feedbacks in coupled ocean-atmosphere models. J Climate 19:3354-3360

Soden BJ, Vecchi G (2011) The vertical distribution of cloud feedback in coupled ocean-atmosphere models. Geophys Res Lett 38:L12704. doi:10.1029/2011GL047632

Sohn BJ, Park SC (2010) Strengthened tropical circulations in past three decades inferred from water vapor transport. J Geophys Res 115:D15112. doi:10.1029/2009JD013713

Solomon S, Rosenlof KH, Portmann RW, Daniel JS, Davis SM, Sanford TJ, Plattner GK (2010) Contributions of stratospheric water vapor to decadal changes in the rate of global warming. Science 327:1219-1223

Spencer RW, Braswell WD (1997) How dry is the tropical free troposphere? Implications for global warming theory. Bull Am Meterol Soc 78:1097-1106

Stephens GL, Ellis TD (2008) Controls of global-mean precipitation increases in global warming GCM experiments. J Climate 21:6141-6155

Sugiyama M, Shiogama H, Emori S (2010) Precipitation extreme changes exceeding moisture content increases in MIROC and IPCC climate models. Proc Nat Acad Sci 107:571-575

Takahashi K (2009) The global hydrological cycle and atmospheric shortwave absorption in climate models under $\mathrm{CO}_{2}$ forcing. J Climate 22:5667-5675

Trenberth KE (2002) Changes in tropical clouds and radiation. Science 296:2095a

Trenberth KE (2011) Changes in precipitation with climate change. Climate Res 47:123-138

Vecchi GA, Soden BJ, Wittenberg AT, Held IM, Leetmaa A, Harrison MJ (2006) Weakening of tropical pacific atmospheric circulation due to anthropogenic forcing. Nature 441:73-76

Wentz FJ, Ricciardulli L, Hilburn K, Mears C (2007) How much more rain will global warming bring? Science 317:233-235

Zahn M, Allan RP (2011) Changes in water vapor transports of the ascending branch of the tropical circulation. J Geophys Res 116:D18111. doi:10.1029/2011JD016206

Zelinka MD, Hartmann DL (2010) Why is longwave cloud feedback positive? J Geophys Res 115:D16117 